\title{
ON THE INCREASE
}

IN NUMBER OF

\section{WHITE CORPUSCLES IN THE BLOOD IN INFLAMMATION,}

\author{
ESPECIALLY IN THOSE CASES ACCOMPANIED \\ BY SUPPURATION.
}

BY

T. P. GOSTLING M.R.C.S., L.R.C.P.,

Diss, NoRfolz.

(Communicated by Dr. RINGER, F.R.S.)

Received October 23rd, 1885-Read January 12th, 1886.

Dr. Ringer, in speaking to me of inflammation, mentioned the fact that although various writers had observed and recorded the increase of white blood-corpuscles in this condition, still this increase had never apparently been observed in a systematic manner in a series of cases, and he suggested that I should make the following observations.

Before doing so, however, I looked up the previous works on this point, and I found that the observers mentioned below had recorded this increase. Unfortunately, they have not all used the same method of counting, some of them having used diluted and others undiluted blood, while some have given their results per cubic millimetre, and others in the relative numbers of the corpuscles only. 
Piorry in $1837^{1}$ concluded from experiments on coagulation of the blood in pneumonia that the white bloodcorpuscles were increased in that disease. Virchow ${ }^{2}$ states that he has found an increased number of white bloodcorpuscles in severe inflammations, especially in pneumonia, the typhoid state, and puerperal fever, and Nasse is quoted as having corroborated this statement as far as some cases of pneumonia are concerned. Concerning the chronic inflammatory conditions, it is stated ${ }^{3}$ that Nasse has found this increase in phthisis, and Virchow and Gulliver have also recorded it in chronic diseases accompanied by hectic. But Malassez, ${ }^{4}$ in 1873, published estimations of conclusions from a series of cases which are so interesting that I venture to quote them rather more fully. In looking over the results recorded by Malassez, however, it must be remembered that he takes 8000 white blood-corpuscles and 5,000,000 red blood-corpuscles as the normal number of corpuscles in a cubic millimetre of blood, which gives the relative number as 1 white to 625 red blood-corpuscles. $\mathrm{He}$ first quotes four cases of facial erysipelas without any complication, and gives estimations made during (1) the continuance of the rash, (2) during convalescence, (3) after complete recovery.

CASE 1.-Woman, æt. 53.

Estimations during the eruption - . 1 W.B.C. to 333 R.B.C.

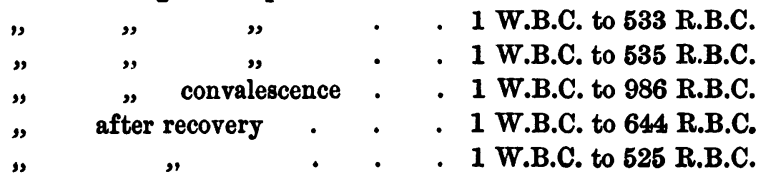

CaSe 2.-Woman, æt. 32.

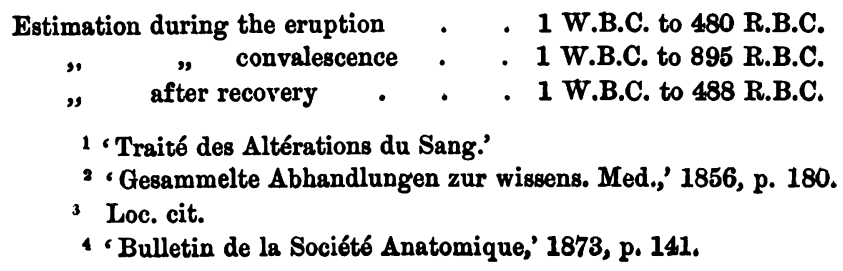


The other two cases are not complete, but they confirm the above figures.

From these cases Malassez concludes that there is :

1. An increase of white blood-corpuscles during the eruption of erysipelas.

2. A decrease of white blood-corpuscles when the eruption disappears.

3. A return of the white blood-corpuscles to their normal number during the week following convalescence.

But the above apparent increase is only relative, because in Case 1, during the eruption, the red blood-corpuscles fell from 4,100,000 per cubic millimetre to $3,600,000$, although, when the eruption faded, the white blood-corpuscles were actually decreased, but not so much as the proportion indicates, because at that time the number of red blood-corpuscles only amounted to $4,000,000$ per cubic millimetre.

In Case 2 also the red blood-corpuscles rose at the end of the disease from $3,700,000$ to $4,100,000$ per cubic millimetre.

Malassez next quotes a case of facial erysipelas followed by suppuration near the sterno-mastoid muscle in which, during the eruption, there was 1 white blood-corpuscle to 400 red blood-corpuscles; when the abscess was forming 1 white blood-corpuscle to 342 red blood-corpuscles; when the abscess had increased in size 1 white blood-corpuscle to 295 red blood-corpuscles; after the pus was removed 1 white blood-corpuscle to 345 red blood-corpuscles, 1 white blood-corpuscle to 385 red blood-corpuscles.

So that in this case of facial erysipelas complicated with suppuration there was no greater increase in the number of the white blood-corpuscles than in an ordinary case of erysipelas, so long as it alone existed, but a further increase was at once observed when suppuration commenced, "and this only ceased when the pus escaped."

Two cases of erysipelas are then related in subjects suffering from chronic enlargement of the cervical glands, which confirm the above observations. 
In the same article it is stated that Vulpian and Troisier had examined three cases of erysipelas, and although these experiments were made with undiluted blood they found that the white blood-corpuscles were increased in each case, and in one of them, in which an abscess was opened at the same time that the erysipelas was cured, the number of white blood-corpuscles in each field of the microscope fell from 25 to 10 .

Liouville and Béhier have also observed the increase of white blood-corpuscles in erysipelas, and Berger, quoting from Klebs, says that the white blood-corpuscles are increased both in suppuration and in pneumonia.

Nicati and Tarchanoff ${ }^{1}$ compare the increase in the number of white blood-corpuscles caused by severe and slight inflammations, and they show that the more severe the inflammation the greater is the increase in the number of the white blood-corpuscles. In comparing the number of white blood-corpuscles contained in the venous blood returning from an inflamed area with the number in the venous blood generally of the body of a rabbit, they found a large increase in the former and a relative increase in the latter.

English writers appear to doubt this increase, if the following passage from Erichsen's ' Surgery' may be taken as fairly expressing their views :- "As to the white corpuscles we know that they are present in augmented numbers in the vessels of the inflamed part; whether they are really more numerous in the blood in inflammation is doubted by Paget, Simon, and others."

The observations recorded by myself in this paper were made with a Gowers' hæmocytometer, as described in Quain's 'Dictionary of Medicine', p. 561. But after some experience I found that practically it was quite sufficient to count the number of red blood-corpuscles in four squares of the cell instead of in ten as Gowers recom. mends, as this gave in the end the same average number of red blood-corpuscles per square as when the larger

1 'Archives de Physiologie normale et pathologique,' 1875, p. 514. 
number of squares were counted, provided that the blood was thoroughly mixed with the diluting fluid. I have also in the following estimations, when counting the white corpuscles, slightly lowered the focus, and have then counted the white blood-corpuscles as dark coloured spots. This plan I have found to be easier, quicker, and quite as correct as that recommended by Gowers, in which the focus is slightly raised and then the white corpuscles counted as bright points.

The results are given in percentage number of red, and relative number of white, blood-corpuscles.

The average number of corpuscles contained in a cubic millimetre of blood is given by Dr. Gowers as 15,000 white and 5,000,000 red blood-corpuscles, which gives a proportion of 1 white blood-corpuscle to 333 red ones.

CASE 1.-Case of iliac abscess, elastic, but not fluctuating at commencement of observations.

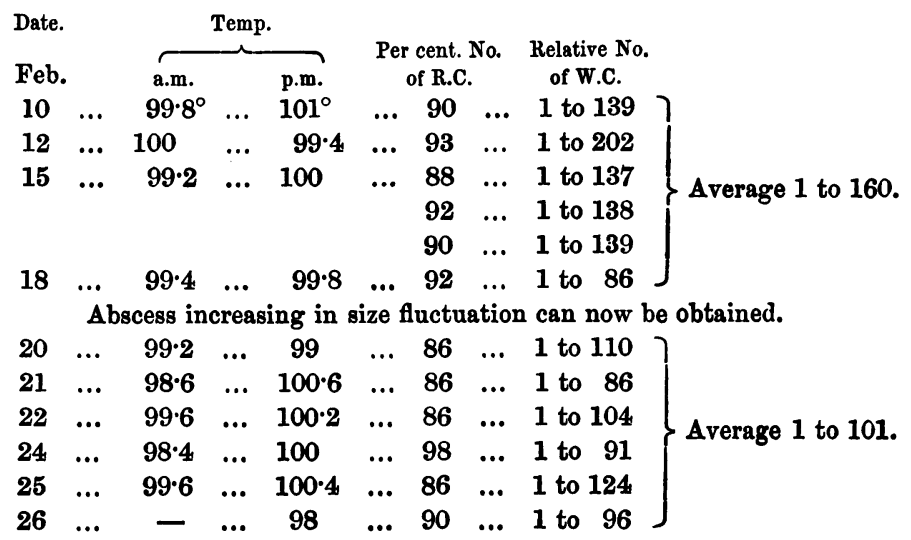

Operation at 2.30 p.m. on Feb. 26, immediately after last observation.

Large amount of pus escaped when abscess was opened.

Free discharge of pus and serum in first 24 hours after incision.

$\left.\begin{array}{ccrrrrrrr}27 & \ldots & 100.2 & \ldots & 101 \cdot 8 & \ldots & 94 & \ldots & 1 \text { to } 383 \\ 28 & \ldots & 97 \cdot 8 & \ldots & 98.6 & \ldots & 90 & \ldots & 1 \text { to } 270 \\ \text { March } & & & & & & & & \\ 1 & \ldots & 98 & \ldots & 98 \cdot 2 & \ldots & 88 & \ldots & 1 \text { to } 304 \\ 2 & \ldots & - & \ldots & 98 \cdot 2 & \ldots & 98 & \ldots & 1 \text { to } 245\end{array}\right)$




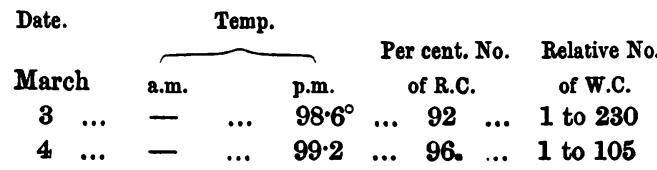

Constipation present; bowels not relieved since opera-

tion. Not thoroughly opened until March 9th.

Discharge much less.

$\begin{array}{lllllllll}5 & \ldots & - & \ldots & 103 & \ldots & 94 & \ldots & 1 \text { to } 114\end{array}$

$\begin{array}{llllllllll}6 & \ldots & 99^{\circ} & \ldots & 98.4 & \ldots & 88 & \ldots & 1 \text { to } 158\end{array}$

$\begin{array}{llllllllll}7 & \ldots & 103 & \ldots & 102 & \ldots & 84 & \ldots & 1 \text { to } 161\end{array}$

$\begin{array}{llllllllll}8 & \ldots & 98.8 & \ldots & 102 \cdot 4 & \ldots & 86 & \ldots & 1 \text { to } 150\end{array}$

$\begin{array}{llllllllll}10 & \ldots & - & \ldots & 99.4 & \ldots & 92 & \ldots & 1 \text { to } 184\end{array}$

$\left.\begin{array}{lllllllll}11 & \ldots & 98 \cdot 4 & \ldots & 98 \cdot 6 & \ldots & 96 & \ldots & 1 \text { to } 240\end{array}\right\}$ Average 1 to 223.

$\begin{array}{llllllllll}12 & \ldots & - & \ldots & 98.4 & \ldots & 96 & \ldots & 1 \text { to } 300\end{array}$

$\begin{array}{llllllllll}13 & \ldots & 98.6 & \ldots & 99.4 & \ldots & 90 & \ldots & 1 \text { to } 250\end{array}$

$\begin{array}{llllllllll}14 & \ldots & 98.4 & \ldots & 98.4 & \ldots & 92 & \ldots & 1 \text { to } 287\end{array}$

$\begin{array}{llllllllll}15 & \ldots & 99.6 & \ldots & 101 & \ldots & 94 & \ldots & 1 \text { to } 213\end{array}$

$\begin{array}{lllllllllll}16 & \ldots & 98 \cdot 4 & \ldots & 98 & \ldots & 88 & \ldots & 1 \text { to } 314\end{array}$

$\begin{array}{llllllllll}17 & \ldots & 98 & \ldots & 98 & \ldots & 90 & \ldots & 1 \text { to } 287\end{array}$

$\left.\begin{array}{llllllllll}19 & \ldots & 98 \cdot 4 & \ldots & 97 \cdot 8 & \ldots & 92 & \ldots & 1 \text { to } 286\end{array}\right\}$ Average 1 to 252.

$\begin{array}{llllllllll}20 & \ldots & - & - & \ldots & 98.2 & \ldots & 94 & \ldots & 1 \text { to } 313\end{array}$

$\begin{array}{lllllllll}21 & \ldots & 98 & \ldots & 98.2 & \ldots & 94 & \ldots & 1 \text { to } 335\end{array}$

$\begin{array}{llllllllll}22 & \ldots & 97.8 & \ldots & 98 & \ldots & 98 & \ldots & 1 \text { to } 272\end{array}$

$\begin{array}{llllllllll}23 & \ldots & 98.4 & \ldots & 98.2 & \ldots & 96 & \ldots & 1 \text { to } 320\end{array}$

$\begin{array}{llllllllll}24 & \ldots & 98.4 & \ldots & 98 \cdot 2 & \ldots & 90 & \ldots & 1 \text { to } 264\end{array}$

$\begin{array}{llllllllll}26 & \ldots & 98 \cdot 4 & \ldots & 97 \cdot 8 & \ldots & 94 & \ldots & 1 \text { to } 361\end{array}$

$\begin{array}{llllllllll}27 & \ldots & - & \ldots & \ldots & 97 \cdot 8 & \ldots & 94 & \ldots & 1 \text { to } 408\end{array}$

March 27th.-Drainage changed for one half the original diameter and length. Discharge almost stopped.

$\left.\begin{array}{ccccccccc}28 & \ldots & 98 \cdot 4 & \ldots & 97 & \ldots & 96 & \ldots & 1 \text { to } 300 \\ 31 & \ldots & 99 & \ldots & 98.4 & \ldots & 96 & \ldots & 1 \text { to } 320 \\ \begin{array}{c}\text { April } \\ 2\end{array} & \ldots & 98 & \ldots & 97 & \ldots & 90 & \ldots & 1 \text { to } 450 \\ 4 & \ldots & - & \ldots & 97 \cdot 4 & \ldots & 96 & \ldots & 1 \text { to } 400\end{array}\right\}$ Average 1 to 358.

Drainage-tube 2 inches long. Discharge nil.

$\begin{array}{rlrllllll}8 & \ldots & - & \ldots & 98 & \ldots & 90 & \ldots & 1 \text { to } 346 \\ 22 & \ldots & - & \ldots & 97 \cdot 4 & \ldots & 88 & \ldots & 1 \text { to } 315\end{array}$

Patient got up on 19th April. The drainage-tube was removed, and the wound had completely closed by the 21st, the patient learing the hospital on April 22nd.

This case is one of iliac abscess coming on about four months after a confinement. On admission to Univer- 
sity College Hospital there was an elastic, tender, and painful swelling in the left iliac fossa reaching two inches above Poupart's ligament. The glands in the groin were enlarged although the skin was not red over the swelling. Observations were made on ten days between February 10th and 26th. During the first half of this period the average relative number of white blood-corpuscles was 1 to 160 , and during the last half, when there was fluctuation in the swelling, 1 to 101, which shows that there was a decided tendency to increase. All this time the swelling was increasing in size, and on February 26th the white blood-corpuscles had reached the relative number of 1 to 96 .

On the following day (February 27th) the abscess was opened and there was an immediate fall to 1 to 383 . After this the white blood-corpuscles increased in number, the average of daily estimations made from February 28th to March 6th (inclusive) being 1 to 203; from March 5th to March 10th there was slight fever, which was supposed to be caused by constipation, but it is quite possible that this rise in temperature was due to a slight increase of inflammation in the walls of the abscess ; and, if this was the cause, the rise in the number of the white blood-corpuscles mentioned above would be accounted for. After March 6th the white blood-corpuscles showed a gradual decrease in number, the averages obtained from two periods of seven days each being 1 to 223 and 1 to 252 . By March 23rd, the abscess cavity had almost entirely filled with granulation tissue, the discharge had almost ceased, and the white blood-corpuscles had become normal in number, viz. 1 to 320 .

From this date to April 22nd, when the wound had been closed fourteen days, the white blood-corpuscles continued to have a normal relation to the red corpuscles, the average being 1 to 358 . 
CASE 2.-Case of pelvic cellulitis. Small swelling in right iliac region, large one in pelvis.

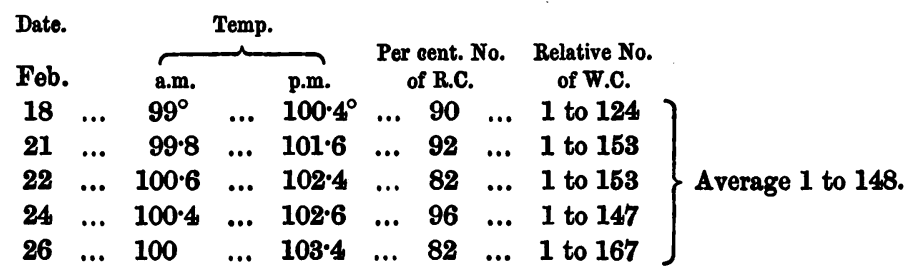

March

$\begin{array}{llllllllll}1 & \ldots & 100 \cdot 2 & \ldots & 103.6 & \ldots & 96 & \ldots & 1 \text { to } 168\end{array}$

Temperature from March 1st to 10th varied from $98 \cdot 8^{\circ}$ a.m. to $103 \cdot 4^{\circ}$ p.m.

$\left.\begin{array}{rrrllllll}10 & \ldots & 101 & \ldots & 103 & \ldots & 86 & \ldots & 1 \text { to } 159 \\ 14 & \ldots & 101 & \ldots & 103 \cdot 8 & \ldots & 94 & \ldots & 1 \text { to } 204 \\ 15 & \ldots & 101 & \ldots & 102 \cdot 4 & \ldots & 86 & \ldots & 1 \text { to } 187 \\ 16 & \ldots & 102 \cdot 2 & \ldots & 103 \cdot 4 & \ldots & 80 & \ldots & 1 \text { to } 166\end{array}\right\}$ Average 1 to 172.

Improvement continued, but at this date it suddenly increased.

On May 17th patient got up after 13 weeks in bed, and left the hospital on May 22nd. 


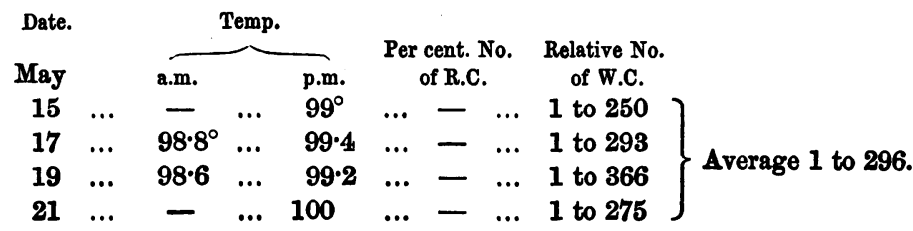

This is another case of pelvic cellulitis, accompanied by well-marked fever and increase in the number of the white blood-corpuscles. The cellulitis came on after an abortion, and when the observations were commenced there was a large tumour in the pelvis, which could be felt both per vaginam and by abdominal palpation. The temperature in this case varied between $99^{\circ}$ a.m. and $103.8^{\circ}$ p.m.

The relative number of white blood-corpuscles from February 18th to May 13th was as under, each number given being the average of five observations made on separate days.

$$
\begin{array}{llllll}
1 & . & . & . & . & 1 \text { to } 148 . \\
2 & . & . & . & . & 1 \text { to } 172 . \\
3 & . & . & . & . & 1 \text { to } 150 . \\
4 & . & . & . & . & 1 \text { to } 158 . \\
5 & . & . & . & . & 1 \text { to } 167 .
\end{array}
$$

During the above period there was abdominal pain, tenderness, loss of appetite, flesh, and strength, but on May 15th the temperature became normal and the symptoms disappeared; during the next few days the patient rapidly became convalescent, and it was found that the swelling in the pelvis was certainly smaller.

On the same date (May 15th) the relative number of white corpuscles decreased to 1 to 250 , and they continued to decrease until, on May 19th, there was only 1 white to 366 red blood-corpuscles, the patient leaving the hospital cured on May 22nd.

On looking at this case and observing the sudden fall of temperature, accompanied by loss of symptoms and dimi- 
nution in the size of the swelling, we may infer, with the physician who had charge of the case, that an abscess had discharged itself into the bowel, an opinion that he formed without knowing that the white blood-corpuscles had been counted, and we may also presume that the diminution in the number of the white blood-corpuscles, which occurred at the same time, was due to this escape of pus, and that it corresponds with the diminution seen to occur in Case No. 1 when the abscess was opened.

CASE 3.-Case of suppurating white leg. No observations until there was distinct fluctuation.

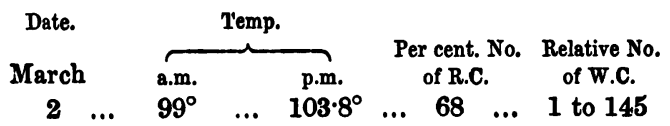

Abscess opened antiseptically; about 5 ounces of blood-stained pus escaped from beneath the soleus.

$$
\left.\begin{array}{ccccccccc}
3 & \ldots & 100 \cdot 2 & \ldots & 102 \cdot 6 & \ldots & 74 & \ldots & 1 \text { to } 133 \\
4 & \ldots & 100 & \ldots & 102 & \ldots & 90 & \ldots & 1 \text { to } 122 \\
5 & \ldots & 98 \cdot 2 & \ldots & 101 \cdot 2 & \ldots & 81 & \ldots & 1 \text { to } 175
\end{array}\right\} \text { Average } 1 \text { to } 143 .
$$

Drainage not altogether perfect, but wound is granulating. Wound quite superficial. Patient to leave hospital on March 23rd.

$\begin{array}{lllllllll}22 & \ldots & 98.4 & \ldots & 98 \cdot 2 & \ldots & 88 & \ldots & 1 \text { to } 338\end{array}$

The whole of the right leg was swollen, cdematous, and tender, with distinct redness over the centre of the calf where deep fluctuation could be obtained.

The temperature ranged, as is shown in the above table, from $99^{\circ}$ a.m. to $103 \cdot 8^{\circ}$ p.m.

Before the pus was evacuated there was one white bloodcorpuscle to 145 red ones, while the average for three days immediately following its evacuation was one to 143 . During these days there was a fair amount of fever, the highest point reached during this time being $102.6^{\circ}$; but eventually, when the temperature became normal, the number of white blood-corpuscles became normal also.

This case appears to confirm what we have seen in part of Case 1, in which after the abscess had been opened, there 
was a slight rise of temperature accompanied by an increase in the number of white blood-corpuscles; but there was an important difference in the two cases, because while Case 1 was perfectly sweet, Case 3 at this time was slightly fœetid and badly drained.

Casm 4.-Case of double suppurative tonsillitis. First observation on fifth day of illness.

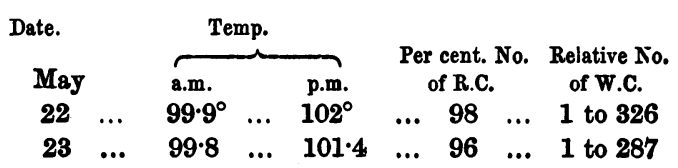

Left tonsil discharged pus at 3 a.m. on May 24th.

Observation made at 7 a.m.

$$
\begin{array}{lllllllll}
24 & \ldots & 98 \cdot 4 & \ldots & 102 \cdot 2 & \ldots & 98 & \ldots & 1 \text { to } 204
\end{array}
$$

Right tonsil discharged pus at 7 a.m. on May 25th.

Observation made at 8 a.m.

$$
\begin{array}{rrrrrrrrr}
25 & \ldots & 101 & \ldots & 102 \cdot 2 & \ldots & 96 & \ldots & 1 \text { to } 369 \\
26 & \ldots & 98 \cdot 8 & \ldots & 98 \cdot 8 & \ldots & 92 & \ldots & 1 \text { to } 270 \\
28 & \ldots & 98 \cdot 2 & \ldots & 98 & \ldots & 100 & \ldots & 1 \text { to } 500
\end{array}
$$

Patient discharged well on May 28th.

No treatment used in course of case except ice to suck.

This case shows a slight but gradual increase in the number of white blood-corpuscles while the abscesses were forming, and this continued until both had discharged their contents, when the number of white blood-corpuscles at once fell to normal ; the case also apparently confirms that which we may infer from the previous ones, viz. that the increase in the number of white blood-corpuscles is less in cases in which there are small, than in those in which there are large, abscesses.

Thus in Case 1, pelvic abscess, the highest average was 1 to 101 ; in Case 2, small pelvic abscess, the highest average was 1 to 150 ; in Case 3 , small abscess in calf, the highest number was 1 to 145 ; while in Case 4, suppurative tonsillitis, the observation which shows the 
largest number of white blood-corpuscles only gives 1 white to 204 red corpuscles.

The following estimations were made in two cases in which the actual cautery was applied for white swellingone of the knee, the other of the shoulder.

CaSE 5.-Case of white swelling of knee treated by actual cautery. First observation made five hours after operation.

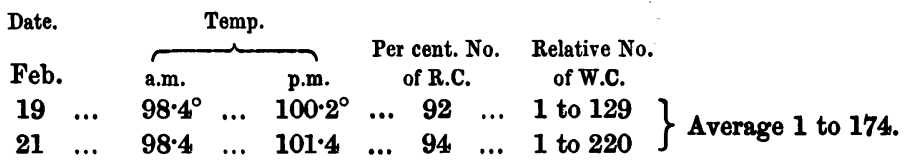

Marks left by cautery are now secreting pus; they are dressed with savin ointment.

$\left.\begin{array}{ccccccccc}22 & \ldots & 100 \cdot 6 & \ldots & 102 & \ldots & 88 & \ldots & 1 \text { to } 304 \\ 24 & \ldots & 99 \cdot 4 & \ldots & 99 \cdot 8 & \ldots & 92 & \ldots & 1 \text { to } 328 \\ 26 & \ldots & 99 & \ldots & 99 & \ldots & 96 & \ldots & 1 \text { to } 332\end{array}\right\}$ Average 1 to 321.

CASE 6.-Case of strumous disease of the shoulder-joint treated by actual cautery. First observation four hours after operation. After operation the shoulder was kept at absolute rest. No irritation applied.

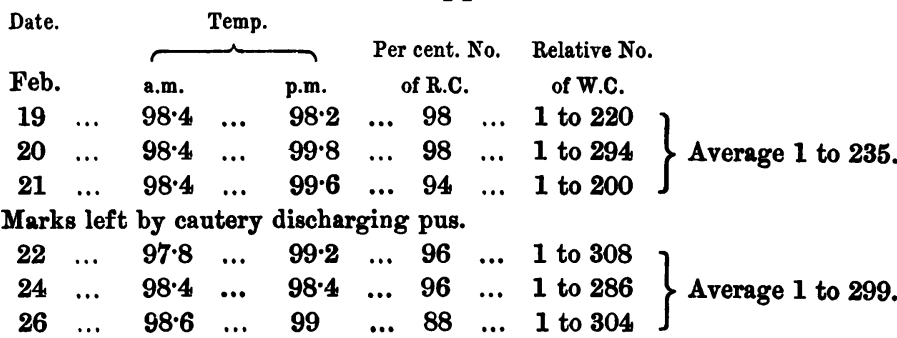

In Case 5 there was rather more inflammation, as shown by the temperature which reached $100.2^{\circ}$, than there was in Case 6, where it only reached $99.8^{\circ}$, but in Case 5 there was also a much larger increase in the number of the white corpuscles after the operation than in Case 6, the average number in Case 5 being 1 to 174, while the average in Case 6 was 1 to 235 .

Both cases were suppurating freely on the fourth day after 
cauterisation, and there was no retention of discharge in either case. In both on the fourth day there was a marked decrease in the number of white blood-corpuscles.

In Case 5 they fell from 1 to 220, to 1 to 304, and in Case 6 they fell from 1 to 200, to 1 to 308 .

After this day the averages show a near approach to the normal number of white blood-corpuscles, being in Case 5 1 to 321, and in Case 61 to 299.

I will next quote four cases of empyema in which observations were made both before and after the chest was drained.

CASE 7.-Case of empyema; about ten ounces of seropurulent fluid removed by aspiration before admission to hospital. Aspiration repeated on April 27th and 29th, and about two ounces of pus removed each time, but on each occasion the needle became blocked by flaky lymph. Observations before aspiration showed a large increase of white corpuscles, but the figures have been lost.

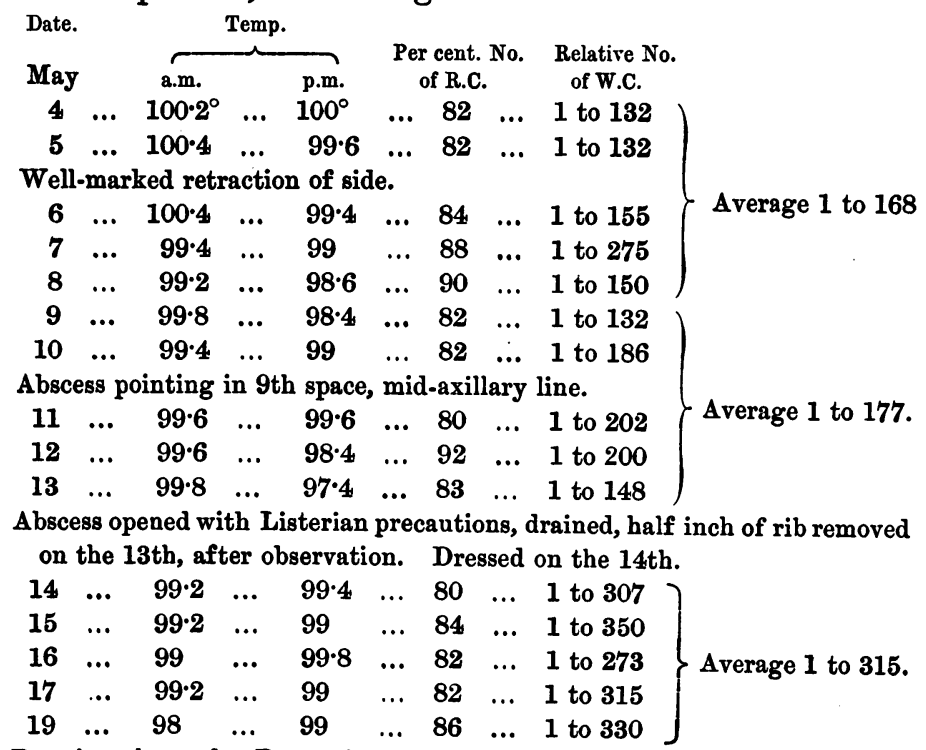

Dressing changed. Retraction much more marked, 


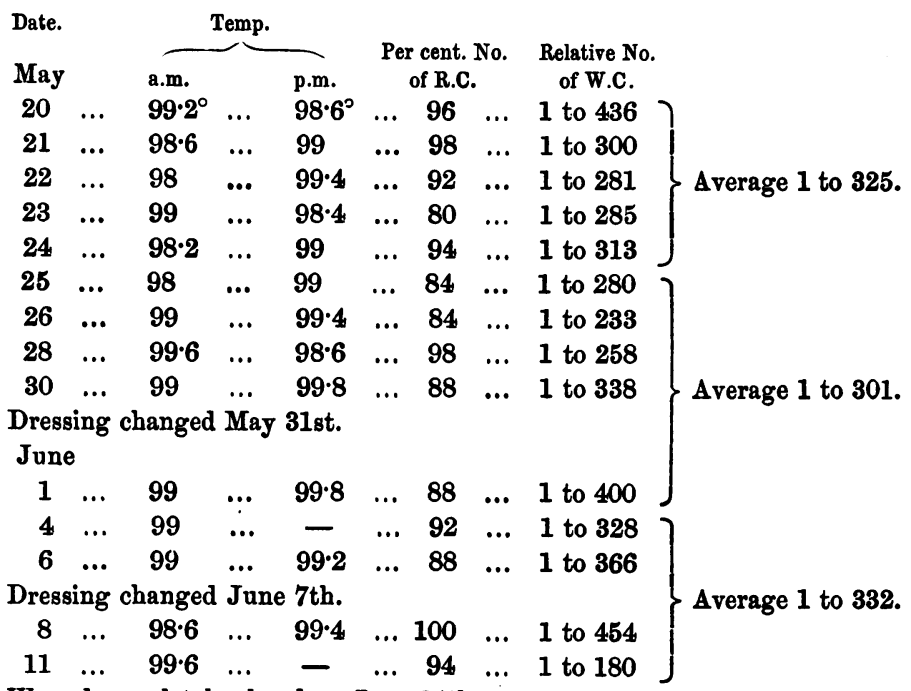

Wound completely closed on June 24th.

This case occurred in a child, aged seven, in whom the signs of fluid in the right pleural cavity were well marked. On admission to the hospital, although about ten ounces of sero-purulent fluid had been previously withdrawn by aspiration, very little fluid could be obtained; repeated attempts to aspirate were made both with and without an anæsthetic, on each occasion the needle becoming blocked. Observations were made daily from May 4th to 13th as to the number of white corpuscles, and it was found that the first five days gave an average of 1 to 168, and the second five days an average of 1 to 177 , results which are practically the same.

At the commencement of this series of observations, which was about fourteen days after admission, there was well-marked retraction of the whole of the right side of the chest. On May 9th it was noticed that the empyema was pointing, and on May 13th the chest was opened and drained, half an inch of rib being removed and a large amount of thick curdy pus being evacuated. The day 
before the operation the relative amount of white to red corpuscles was 1 to 148 ; the day after, it had fallen to 1 to 307 , the temperature remaining as before, just above normal, i.e. $99 \cdot 2^{\circ}$ a.m. and $99 \cdot 4^{\circ}$ p.m.

The average relative number of white corpuscles from May 14th to May 19th, which were the days immediately following the evacuation of the pus, was 1 to 315 , which contrasts strongly with the averages before the operation. From May 19th until June 11th nineteen observations were made on separate days, and averages from these, divided into four periods, are given below :

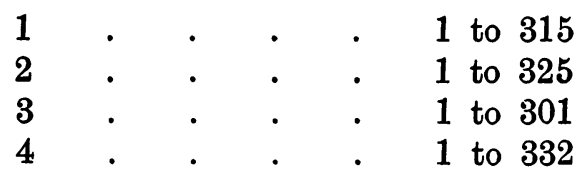

figures which show a very close approach to the normal number.

On June 24th the patient left the hospital, the wound being completely closed.

CASE 8.-Case of empyema. Left side. Aspirated on May 7th. The average relative number of white bloodcorpuscles was 1 to 187 before the chest was opened.

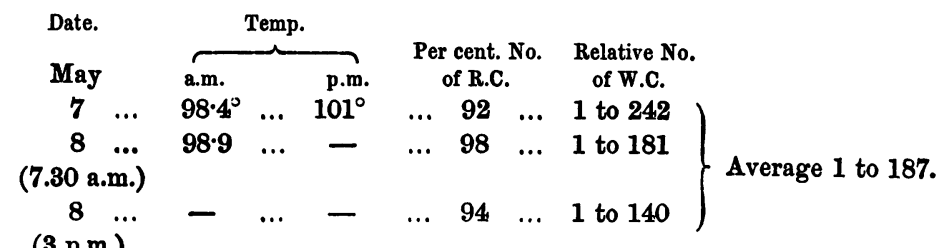

(3 p.m.)

Abscess opened May 8th, drained, 50 ounces of pas removed.

Dressed first time on 9 th.

$\left.\begin{array}{rrrrrrrrr}9 & \ldots & 98 \cdot 6 & \ldots & 99 \cdot 8 & \ldots & 92 & \ldots & 1 \text { to } 200 \\ 10 & \ldots & 99 \cdot 2 & \ldots & 99 \cdot 6 & \ldots & 88 & \ldots & 1 \text { to } 258 \\ 11 & \ldots & 100 \cdot 2 & \ldots & 101 \cdot 2 & \ldots & 90 & \ldots & 1 \text { to } 300 \\ 12 & \ldots & 100 \cdot 6 & \ldots & 101 \cdot 4 & \ldots & 92 & \ldots & 1 \text { to } 328\end{array}\right\}$ Average 1 to 273.




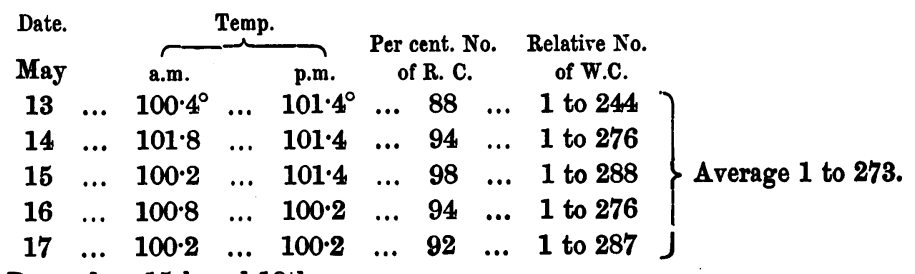

Dressed on 15th and 18th.

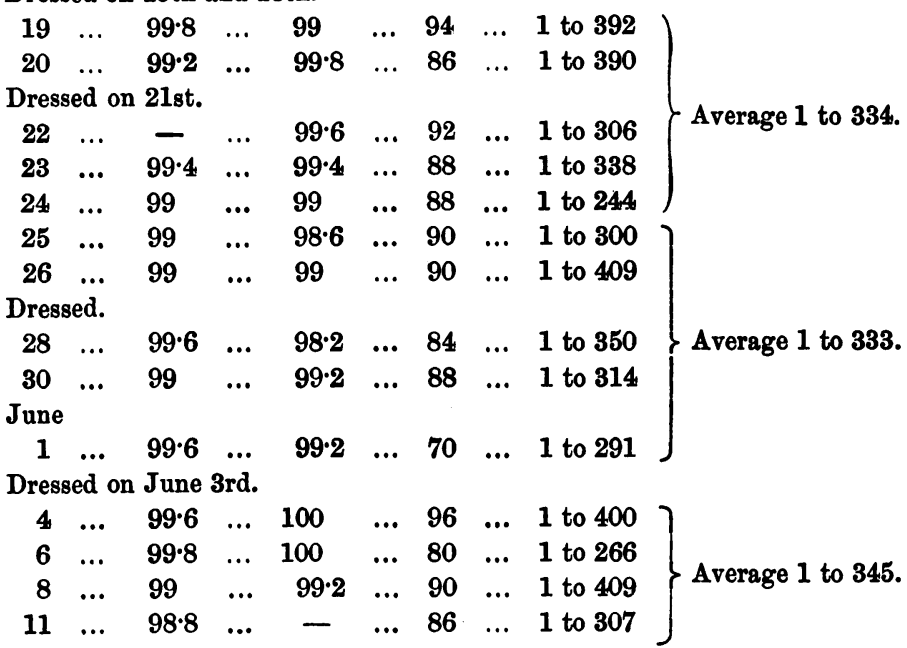

After the operation, however, although there was a considerable fall in the number of white blood-corpuscles, they did not fall to normal, the average obtained from nine daily observations, from May 9 th to 17 th, after the chest was opened and drained, being 1 to 273 . Possibly this might be accounted for by the fact that in this case the patient was an adult, and as no bone was removed the chest did not drain satisfactorily at first.

After May 17th, however, the proportion of white to red corpuscles again fell, the averages for three periods of five days each being: 1 to 334,1 to 333,1 to 345 , which figures show even a closer approach to the normal than was obtained in Case 7.

The observations were continued until June 11th, when the patient was lost sight of, as he left the hospital, although there was still a small sinus. 
CASE 9.-Case of empyema in a child, following on pneumonia.

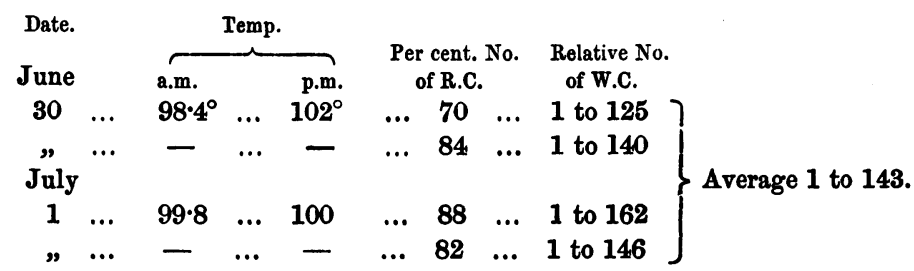

July 1st.-Free incision, $8 \mathrm{oz}$. of pus evacuated; half inch of rib removed. Next observation 8 hours after operation.

July

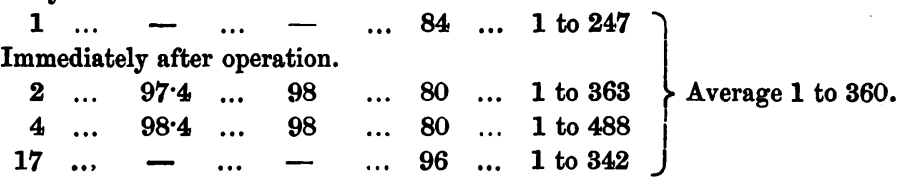

This case corresponds almost exactly to Case 7, the proportions being as under.

Previous to operation the average of four estimations made on two days was 1 to 143 .

After operation the average of four estimations made on four separate days was 1 to 360 .

In this case also the fall in the number of white bloodcorpuscles was observed the day after the operation, the number the day before being 1 to 146 , and the number the day after being 1 to 363 .

CASE 10.-Case of right empyema in a puerperal woman. Date.

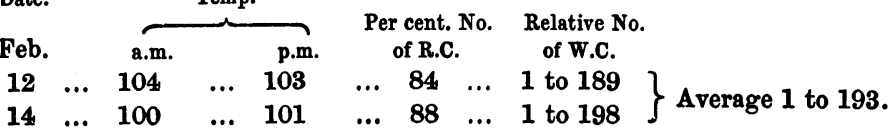

Pus evacuated by incision; a large amount removed.

$\left.\begin{array}{rrrrrrrrrr}16 & \ldots & 100 \cdot 8 & \ldots & 98 \cdot 8 & \ldots & 84 & \ldots & 1 \text { to } 180 \\ 18 & \ldots & 97 \cdot 4 & \ldots & 97 \cdot 4 & \ldots & 88 & \ldots & 1 \text { to } 190 \\ 19 & \ldots & 98.8 & \ldots & 99 \cdot 6 & \ldots & 92 & \ldots & 1 \text { to } 192\end{array}\right\}$ Average 1 to 187.

Death occurred on Feb. 19.

At post-mortem no further collection of pus was found. 
CASE 10 is an empyema that occurred in a puerperal woman; it is only useful to show the increase of white blood-corpuscles in the presence of a collection of pus, the average relative number being 1 to 193 .

The chest was opened four days before death, but this could hardly be expected to diminish the number of the white blood-corpuscles in a patient in such a condition, the average obtained from the estimation made after the operation being 1 to 187 .

The observations made on these four cases of empyema corroborate those made on the cases of suppurative cellulitis, viz. that wherever there is a collection of pus there is an appreciable increase in the relative number of white blood-corpuscles, which falls as soon as this pus is evacuated.

The next three cases, 11,12 , and 13 , are a series of observations made on phthisical patients with cavities and free expectoration; these all show a slight increase in white blood-corpuscles, as has been previously recorded by Nasse.

CASE 11.-Phthisis cavities over the whole of right lung, copious muco-purulent expectoration.

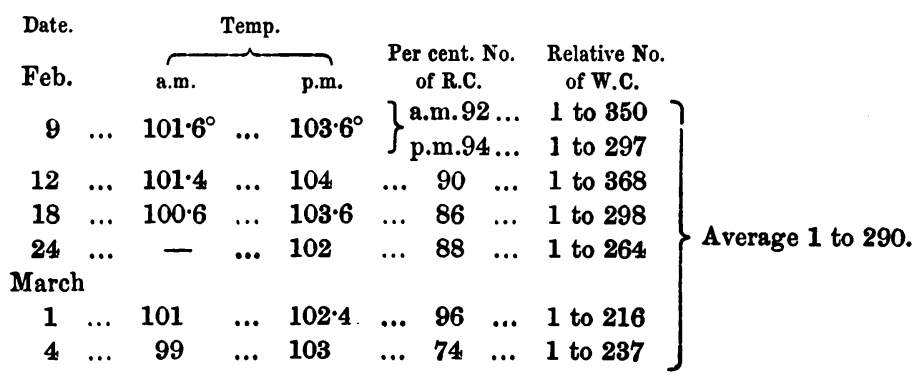

CASE 12.-Phthisis cavity at left apex, moderate amount of muco-purulent expectoration. 


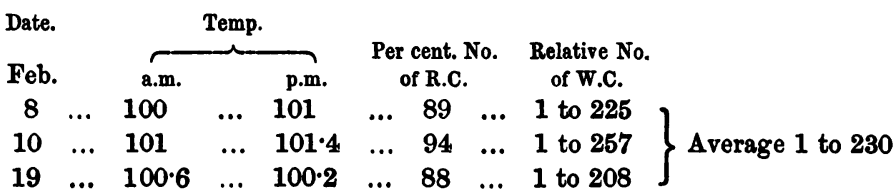

CASE 13.-Phthisis cavities at both apices, muco-purulent expectoration. Spinal caries, psoas abscess, open, badly drained.

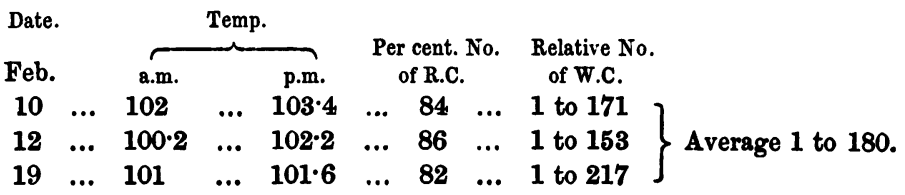

Cases 11 and 12 are comparable to the case of iliac abscess which is recorded as Case 1 .

This similarity is found in the fact that after the abscess in Case 1 was opened we have three patients in each of whom there is a cavity or cavities (although in different parts of the body) secreting pus in considerable quantities, the pus in each of the cases having comparatively free exit. It is also shown in the relative numbers of the white bloodcorpuscles which are given below :

Averages from Case 1.-1 to 203, 1 to 223, 1 to 252.

Average from Case 11.-1 to 290 .

Average from Case 12.-1 to 230.

Case 13 was, however, complicated by an open, badlydrained psoas abscess depending on spinal caries, and in this case we find that the relative number of white blood-corpuscles is increased not only above the normal, but also above the increase found in Cases 11 and 12, which are ordinary cases of phthisis ; just as one might be led to expect from the observations made in Cases 3 and 8 , in both of which there were abscess cavities badly drained.

In Case 13 the proportion of white and red corpuscles is 1 to 180 ; in 11 and 12 it is 1 to 290 , and 1 to 230 ; while in Cases 3 and 8, whilst they were badly drained, it was 1 to 143 , and one to 272 . 
CaSE 14.-Left pleurisy with serous effusion. Friction on April 27th. Serous fluid obtained on May 6th, which coagulated spontaneously. Movements diminished. Vocal fremitus absent. Breath-sounds absent. Heart's impulse on right of sternum.

\begin{tabular}{|c|c|c|c|c|c|c|c|c|c|}
\hline Date. & & & Temp & & & & & & \\
\hline May & & a.m. & & p.m. & & $\begin{array}{l}\text { cent. } \\
\text { f R.C }\end{array}$ & No. & $\begin{array}{l}\text { Relative No. } \\
\text { of W.C. }\end{array}$ & \\
\hline 5 & $\ldots$ & $100 \cdot 6^{\circ}$ & $\ldots$ & $103 \cdot 6^{\circ}$ & $\ldots$ & 90 & ... & 1 to 264 & \\
\hline 6 & $\ldots$ & $101 \cdot 2$ & $\ldots$ & $103 \cdot 6$ & $\ldots$ & 82 & $\ldots$ & 1 to 292 & \\
\hline 7 & $\ldots$ & $100 \cdot 6$ & $\ldots$ & $102 \cdot 6$ & $\ldots$ & 86 & ... & 1 to 330 & \\
\hline 8 & $\ldots$ & $100 \cdot 6$ & $\ldots$ & $103 \cdot 2$ & $\ldots$ & 92 & $\ldots$ & 1 to 306 & \\
\hline 9 & $\ldots$ & $100 \cdot 6$ & $\ldots$ & $103 \cdot 2$ & $\ldots$ & 92 & ... & 1 to 383 & verage 1 to 336 . \\
\hline 10 & $\ldots$ & $102 \cdot 6$ & $\ldots$ & $103 \cdot 4$ & $\ldots$ & 88 & $\ldots$ & 1 to 400 & \\
\hline 11 & $\ldots$ & $100 \cdot 6$ & $\ldots$ & 103 & $\ldots$ & 86 & $\ldots$ & 1 to 390 & \\
\hline 12 & $\ldots$ & $101 \cdot 4$ & $\ldots$ & $103 \cdot 4$ & $\ldots$ & 98 & $\ldots$ & 1 to 326 & \\
\hline
\end{tabular}

Heart's impulse still on right of sternum. Vocal fremitus at level of nipple, in anterior maxillary fold. No V.F. below this. Friction present.

$$
\left.\begin{array}{ccccccccc}
13 & \ldots & 100 \cdot 8 & \ldots & 102 \cdot 2 & \ldots & 88 & \ldots & 1 \text { to } 400 \\
14 & \ldots & 100 \cdot 4 & \ldots & 101 & \ldots & 92 & \ldots & 1 \text { to } 353 \\
15 & \ldots & 100 \cdot 2 & \ldots & 100 \cdot 6 & \ldots & 92 & \ldots & 1 \text { to } 418 \\
16 & \ldots & 99 & \ldots & 100 \cdot 8 & \ldots & 86 & \ldots & 1 \text { to } 390 \\
17 & \ldots & 98 & \ldots & 100 \cdot 6 & \ldots & 90 & \ldots & 1 \text { to } 500
\end{array}\right\} \text { Average } 1 \text { to } 412 .
$$

No pulsation on right of sternum. Heart's apex beat felt in 4th space, left side, inside nipple. No friction. Vocal fremitus felt quite to the base.

$$
\left.\begin{array}{cccllllll}
19 & \ldots & 98 \cdot 6 & \ldots & 98 \cdot 4 & & & & \\
20 & \ldots & 98 \cdot 6 & \ldots & 99 & \ldots & 96 & \ldots & 1 \text { to } 480 \\
21 & \ldots & 98 \cdot 6 & \ldots & 98 \cdot 8 & \ldots & 88 & \ldots & 1 \text { to } 440 \\
22 & \ldots & 98 \cdot 6 & \ldots & 99 & \ldots & 96 & \ldots & 1 \text { to } 436 \\
23 & \ldots & 98 \cdot 6 & \ldots & 99 & \ldots & 98 & \ldots & 1 \text { to } 445 \\
24 & \ldots & 98 \cdot 6 & \ldots & 98 & \ldots & 90 & \ldots & 1 \text { to } 321 \\
26 & \ldots & - & \ldots & 98 \cdot 8 & \ldots & 80 & \ldots & 1 \text { to } 400 \\
30 & \ldots & 98 \cdot 4 & \ldots & 99 \cdot 4 & \ldots & 86 & \ldots & 1 \text { to } 430
\end{array}\right\} \text { Average } 1 \text { to } 421 .
$$

Patient was discharged on June 1st, with slight deficient resonance at left base, also with slight deficient movement and slight retraction of left side.

Here there was no increase in the number of the white blood-corpuscles whilst any fluid remained, the relative number being, from an average of eight observations, 1 to 336. 
CORPUSCLES IN THE BLOOD IN INFLAMMATION. 203

During convalescence, however, there was a decided diminution in their number, the averages being, during a period of five and seven days respectively, 1 to 412 and 1 to 421 .

Here we have a case in which there was a considerable amount of inflammation, as is evident from the large amount of serous fluid which was present, and which was accompanied by high fever, the temperature varying from $100 \cdot 6^{\circ}$ a.m. to $103 \cdot 6^{\circ}$ p.m., but in which there was no increase in the number of white blood-corpuscles.

May we therefore infer from this that a special variety of inflammation is necessary in order to cause their increase?

CaSE 15.-Case of left serous pleurisy with effusion. Aspirated on May 4th after estimation. Fifty-two ounces of fluid withdrawn.

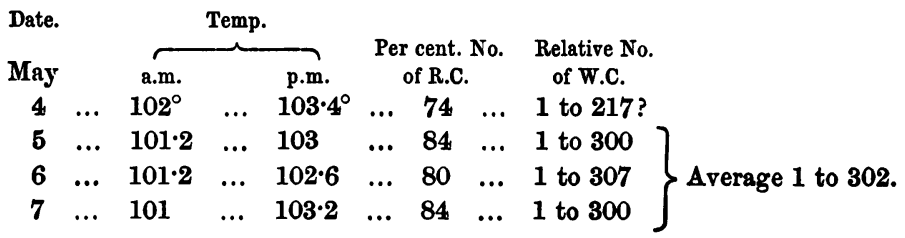

$36 \mathrm{oz}$. of fluid withdrawn by the aspirator.

$$
\left.\begin{array}{rllllllll}
8 & \ldots & 101 \cdot 6 & \ldots & 103 & \ldots & 92 & \ldots & 1 \text { to } 383 \\
9 & \ldots & 102 & \ldots & 103 \cdot 6 & \ldots & 90 & \ldots & 1 \text { to } 346 \\
10 & \ldots & 101 \cdot 2 & \ldots & 102 & \ldots & 84 & \ldots & 1 \text { to } 466 \\
11 & \ldots & 100 \cdot 6 & \ldots & 102 \cdot 2 & \ldots & 90 & \ldots & 1 \text { to } 409 \\
12 & \ldots & 101 & \ldots & 102 \cdot 4 & \ldots & 90 & \ldots & 1 \text { to } 321
\end{array}\right\} \text { Average } 1 \text { to } 385 .
$$

Vocal fremitus felt at extreme base. Slight dulness at left base. Breathsounds heard at extreme base. Slight cough and mucoid expectoration, streaked with blood.

$\left.\begin{array}{ccccccccc}13 & \ldots & 101 & \ldots & 102 \cdot 4 & \ldots & 78 & \ldots & 1 \text { to } 433 \\ 14 & \ldots & 101 \cdot 2 & \ldots & 102 \cdot 4 & \ldots & 86 & \ldots & 1 \text { to } 430 \\ 15 & \ldots & 99 \cdot 8 & \ldots & 102 \cdot 6 & \ldots & 90 & \ldots & 1 \text { to } 450 \\ 16 & \ldots & 100 \cdot 4 & \ldots & 102 \cdot 2 & \ldots & 92 & \ldots & 1 \text { to } 511 \\ 17 & \ldots & 101 \cdot 6 & \ldots & 101 \cdot 8 & \ldots & 86 & \ldots & 1 \text { to } 377 \\ 19 & \ldots & 100 \cdot 2 & \ldots & 100 \cdot 6 & \ldots & 84 & \ldots & 1 \text { to } 381 \\ 20 & \ldots & 99 & \ldots & 100 \cdot 8 & \ldots & 82 & \ldots & 1 \text { to } 410 \\ 22 & \ldots & 99 \cdot 6 & \ldots & 99 \cdot 6 & \ldots & 88 & \ldots & 1 \text { to } 366 \\ 23 & \ldots & 99 \cdot 2 & \ldots & 99 \cdot 2 & \ldots & 88 & \ldots & 1 \text { to } 314 \\ 24 & \ldots & 99 \cdot 2 & \ldots & 99 \cdot 8 & \ldots & 84 & \ldots & 1 \text { to } 420\end{array}\right\}$ Average 1 to 440.




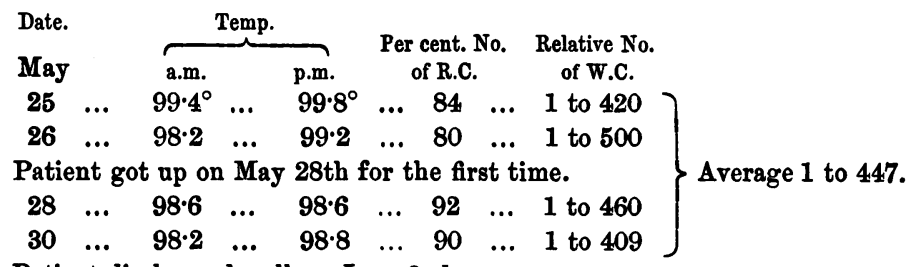

Patient discharged well on June 2nd.

This case is similar in all its characters to the last, except that here aspiration was employed twice, and fifty-two ounces and thirty-six ounces of fluid were withdrawn on the respective occasions, while in Case 14 this was not done.

In this case the averages are, while fluid was present, 1 to 302 and 1 to 385 ; during convalescence, 1 to 440,1 to 378 , and 1 to 447 .

These two cases form a very marked contrast with the cases of empyema previously spoken of, in which the white blood-corpuscles were very largely increased.

CASE 16.-Case of lobar pneumonia, left base. Illness commenced on May 30th. Observations commenced on June 3rd, being fifth day of disease.

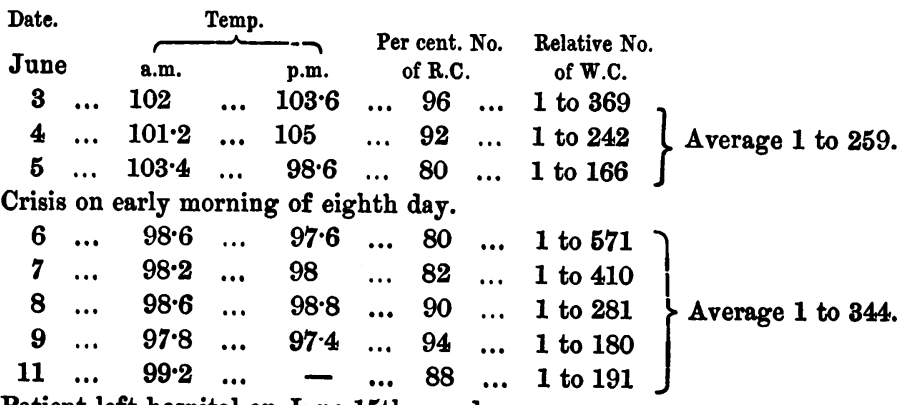

Patient left hospital on June 15th cured.

This case is one of a different class, the observations having been made in a pneumonic patient. It shows a curious increase in number of the white blood-corpuscles up to the crisis of the disease as they gradually increased from 1 to 369 to 1 to 166 . 
At the crisis of the case there occurred a very sudden decrease in their number, the table showing a fall from 1 to 166 to 1 to 571, and then a gradual rise during resolution until they reached 1 to 191 .

This may be the usual course in pneumonia, but it is the only case of this disease which I have estimated, and while it confirms the opinions of Virchow and Nasse as to the increase of white blood-corpuscles in pneumonia it can be taken as proving nothing further.

CASE 17.-Case of typhoid fever, with constipation. Observations commenced on first day of illness.

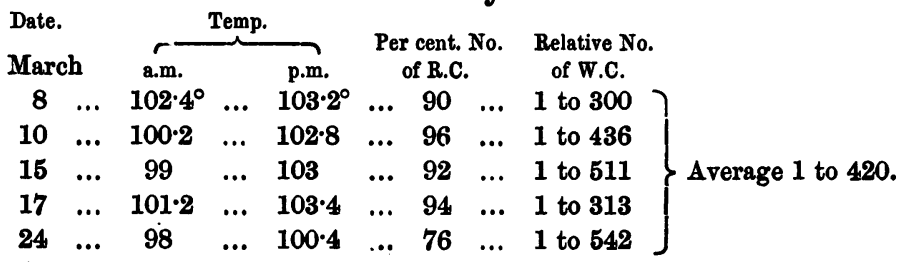

After a relapse temperature became normal on March 26th. On April 7th there was slight periostitis of tibia.

April

$\left.\begin{array}{rrrrrrrrrr}9 & \ldots & 98 \cdot 6 & \ldots & 99 \cdot 2 & \ldots & 92 & \ldots & 1 \text { to } 287 \\ 10 & \ldots & 98 \cdot 4 & \ldots & 99 \cdot 2 & \ldots & 92 & \ldots & 1 \text { to } 418 \\ 10 & 5.30 & \text { p.m. abscess } & \text { opened } & \ldots & 98 & \ldots & 1 \text { to } 490 \\ 11 & \ldots & 98 \cdot 4 & \ldots & 98 \cdot 4 & \ldots & 92 & \ldots & 1 \text { to } 383 \\ 12 & \ldots & - & \ldots & 98.4 & \ldots & 98 & \ldots & 1 \text { to } 376\end{array}\right\}$ Average 1 to 390.

CASE 18.-A case of typhoid, accompanied by high fever, great delirium. Death on twenty-second day of illness. Post-mortem showed extensive and well-marked ulceration of intestine. Observations commenced on twenty-second day of disease.

\begin{tabular}{|c|c|c|c|c|c|c|c|c|c|}
\hline \multirow{2}{*}{\multicolumn{2}{|c|}{$\begin{array}{l}\text { Date. } \\
\text { June }\end{array}$}} & \multicolumn{3}{|c|}{ Temp. } & \multirow{2}{*}{\multicolumn{3}{|c|}{$\begin{array}{l}\text { Per cent. No. } \\
\text { of R.C. }\end{array}$}} & \multirow[b]{2}{*}{$\begin{array}{l}\text { Relative No. } \\
\text { of W.C }\end{array}$} & \multirow{10}{*}{ Average 1 to 486} \\
\hline & & a.m. & & p.m. & & & & & \\
\hline 3 & $\ldots$ & 99 & $\ldots$ & 104 & $\ldots$ & 100 & $\ldots$ & 1 to 652 & \\
\hline 4 & $\ldots$ & $102 \cdot 2$ & $\ldots$ & $103 \cdot 6$ & $\ldots$ & 86 & ... & 1 to 537 & \\
\hline $\mathbf{5}$ & $\ldots$ & 103 & ... & $104 \cdot 6$ & $\ldots$ & 86 & ... & 1 to 537 & \\
\hline 6 & $\ldots$ & $103 \cdot 6$ & $\ldots$ & $104 \cdot 2$ & $\ldots$ & 80 & ... & 1 to 363 & \\
\hline 7 & $\ldots$ & $101 \cdot 6$ & $\ldots$ & 104 & $\ldots$ & 96 & $\ldots$ & 1 to 480 & \\
\hline 8 & $\ldots$ & 102 & $\ldots$ & $104 \cdot 2$ & $\ldots$ & 98 & $\ldots$ & 1 to 445 & \\
\hline 9 & $\ldots$ & $103 \cdot 2$ & $\ldots$ & $105 \cdot 2$ & $\ldots$ & 88 & ... & 1 to 366 & \\
\hline 11 & $\cdots$ & 102 & ... & $104 \cdot 2$ & & 82 & ... & 1 to 512 & \\
\hline
\end{tabular}


Cases 17 and 18 are two ordinary cases of typhoid fever, both of which show a very decided decrease in the relative numbers of the white blood-corpuscles, in Case 17 the proportion being 1 to 420, and in Case 181 , to 486.

But again, these results depend on two cases only, and as the patients were in each case delirious, some difficulty was experienced in obtaining the blood necessary for the estimations, so that an error may easily have occurred. This may account for the fact that the above results differ from those given by Virchow, who states, "that the white corpuscles are increased in the typhoid state."

CaSE 19.-Case of acute rheumatism. Slight effusion in left wrist and left ankle.

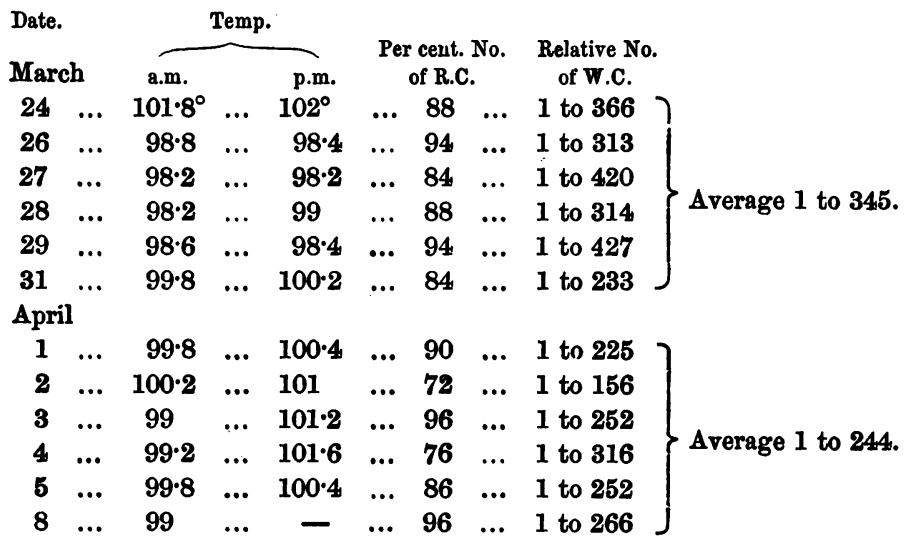

This last case is one of rheumatic fever, in which there was slight effusion into the left. wrist and ankle.

In the first half of this case there is no increase at all in the number of the white blood-corpuscles, which for six estimations on separate days gives an average of 1 white to 345 red corpuscles, while in the latter half of the case there is a slight increase in their number, the average of six observations being 1 white to 244 red corpuscles.

It is only included in this paper because to a certain extent it corroborates the view suggested by Cases 14 and 
15 that serous inflammations do not cause an appreciable increase in the relative numbers of white blood-corpuscles.

The preceding are the cases in which I have made estimations of the number of white corpuscles; they include, as we have seen, the following :

Case 1. Iliac abscess.

„2. Pelvic cellulitis and probably abscess.

„3. Suppurating white leg.

"4. Suppurating tonsillitis.

„5, 6. White swelling treated by the actual cautery.

, 7, 8, 9, 10. Empyema.

„11, 12, 13. Phthisis.

"14, 15. Serous pleurisy.

„16. Lobar pneumonia.

"17, 18. Typhoid fever.

"19. Acute rheumatism.

In Cases 1 to 4 (abscesses), and 7 to 10 (empyemas), where there was suppuration with pent-up pus, we have in each individual case a marked increase in the number of the white blood-corpuscles so long as this tension remained, but as soon as the pus was evacuated and free drainage established, the number of white corpuscles returned practically to normal.

In Cases 11 and 12 (phthisis) we have suppuration with fairly efficient, but not complete, drainage, and there is corresponding slight increase in the white blood-corpuscles such as we have seen in Case 1 while the abscess cavity was closing by granulation.

However, if we turn to Case 13 (phthisis and psoas abscess), we at once see a much larger relative increase, due probably to the inefficient drainage, for we have seen this same increase in Cases 3 and 7, which were acknow. ledged to be badly drained.

If we now look at the cases of inflammation of serous membranes accompanied by serous or sero-fibrinous exudation we find very different results.

Cases 14 and 15, which are serous pleurisies, and Case 
19, which is a single case of acute rheumatism, show that not only is there no increase in the white corpuscles, but in the pleurisy cases there is even actual decrease during convalescence.

Case 16 (pneumonia) stands by itself, and I can offer no explanation concerning it, as the patient left the hospital and was lost sight of while he still had a large increase of white blood-corpuscles.

In the typhoid cases (Nos. 17 and 18) there was, as we have seen, a large decrease in the numbers of the white blood-corpuscles; this may be usual, but I have explained previously one very possible source of error in these cases.

Cases 5 and 6 are recorded, not to show that there is any increase in the number of the white corpuscles in cases of white swelling, but to show the effect of severe local irritation, and in both we see a decided increase, while the acute inflammation lasted, but this was lost as soon as free suppuration was established.

The above observations confirm the opinions of the continental observers quoted at the commencement of this paper as far as pneumonia and phthisis are concerned, and especially the single observation by Malassez on the decrease in the number of the white corpuscles when tension is removed.

On looking at these results, I think that we are justified in drawing the following conclusions :

1. That white corpuscles are increased in number in suppurative inflammations, especially when accompanied by tension.

2. That they are slightly increased in parenchymatous inflammations.

3. That they are not increased in inflammations accompanied by serous or sero-fibrinous exudations.

Concerning the pathology of the above increase, I do not propose to offer any details, but I would suggest that it may be due to absorption of leucocytes from the inflamed area in the neighbourhood of the abscess.

- It has also occurred to me that the increase noticed in 
CORPOSCLES IN THE BLOOD IN INFLAMMATION. 209

the number of white corpuscles in the case of an empyema might be of diagnostic value if it proves on further observation to be constantly present.

(For report of the discussion on this paper, see 'Proceedings of the Royal Medical and Chirurgical Society,' New Series, vol. ii, p. 37.)

vOL. LXIX. 